\title{
The Potential of Foodservice Operations at Visitor Attractions in Ghana
}

\author{
Augusta Adjei Frempong \\ University of Cape Coast, Cape Coast, Ghana
}

\begin{abstract}
The success of a tourist attraction embeds in the provision of foodservice facilities that has the potential to offer the visitor experiences demanded at the sites. In an attempt to explore the relationships between visitor attractions and foodservice in Ghana, this paper provides evidences from an investigation conducted at six selected visitor attractions at various destinations. Due to the paucity of published data on the concept under investigation, this study included two phases: qualitative followed up with a quantitative research. However, the second one, which was based on a survey involving international and domestic visitors (528), is the main focus of this paper. The information gathered in phase one informed the design for the visitors' survey, whose data were analyzed through the Statistical Product and Service Solutions (SPSS). Findings from the study showed a high demand for foodservices at all attractions. Collaborations among formally trained staff and informal or traditional foodservice outlets to develop local cuisines at visitor attractions offer the potential to positively support the tourism industry in Ghana as well as those of other African countries seeking to develop the tourism sectors of their economies. This paper may also be of interest to the relevant and international bodies such as UNWTO, UNDP, and UNEP who seek to promote the development of sustainable practices.
\end{abstract}

Keywords: local cuisines, tourists/tourism, Ghana, foodservice, visitor attractions

\section{Introduction}

Obtaining a nutritious meal could be one of the greatest pleasures for visiting tourist destinations (Hjalager \& Richards, 2002) as it offers a satisfying feeling that could be carried along for a memorable period of time (Kivela \& Crotts, 2006). For instance, a taste of well-prepared Fufu with accompanying delicious soups in Ghana, or the freshly caught seafood along the beach areas over chilled drinks could create an ambience for food tourists with lasting memories (Wolf, 2006). In recent time, local foods have become a key focus of the travelling public, particularly, those in search of authentic experiences (Chang, Kivela, \& Mak, 2010; Torres, 2002). Studies conducted in various countries have shown that tourists demand genuine and local experiences that are linked to the places they visit (Richards, 2011; Molz, 2007). Currently, visitors want to get closer to absorbing a different way of life in order to have the feeling of being one with the culture of the visited place (Kivela \& Crotts, 2006; Ondimu, 2002). The provision of a wide range of local cuisines has the potential to improve the economic stands of countries as tourists spend a sizeable portion of their disposable incomes at such destinations (Bertella, 2011; Kivela \& Crotts, 2006). Although Ghana has the potential to make some contributions, much is not heard about the country.

Augusta Adjei Frempong, lecturer, Department of Vocational and Technical Education, College of Education Studies, University of Cape Coast. Email: augusad@yahoo.com. 


\section{Tourism and Foodservice Evolution in Ghana}

\section{Overview of Ghana}

Ghana is a developing country located in West Africa; it lies on the Gulf of Guinea, between $5^{\circ}$ and $10^{\circ}$ north of the Equator, $1^{\circ}$ on the East Meridian and $3^{\circ}$ on the West Meridian, and $0^{\circ}$ on the Greenwich Meridian (Torgbuiga, 2003). It has a land area of 238,539 $\mathrm{km}^{2}$, divided into 10 administrative regions (each with a capital town and regional minister) and inhabited by an estimated population of 26 million (Ghana Statistical Service, 2012).

Generally, food crops are cultivated in the country with some foodstuffs imported from Asia and the Americas (Ministry of Tourism, UNDP, \& WTO, 1996). The country has tropical cash crops, such as cocoa, oil palm, citrus fruits, cotton, pineapple, rubber, and cashew.

A variety of wildlife are located in the national parks and reserves, e.g., elephants, lions, leopards, hippopotami, hyenas, buffalos, bongos, warthogs, river hogs, bushbucks, antelopes, porcupines, birds, including both endemic and endangered species (Ministry of Tourism, UNDP, \& WTO, 1996). The majority of the country's visitor resources are located in the rural areas, a location that has an impact upon sustainable aspects of the development of visitor attractions (Ministry of Tourism, UNDP, \& WTO, 1996).

\section{Foodservice Provisions in Ghana}

All 10 regions in the country offer varied menus that have distinct tastes and textures: Banku with okro soup or stew within different regions will have completely different tastes and flavors notwithstanding the use of similar ingredients. The varied foodservice provisions include the large- and medium-sized hotels, in addition to different independent restaurants spread throughout the country that offer international foods such as Chinese, European, Indian, French, Lebanese, Thai, and some Ghanaian dishes (Ghana Tourist Board, 2005). Although there are chances of visitors' acquiring foodservice outlets which offer a variety of meals at Ghanaian attractions, a real taste of the traditional/local cuisines tends to be indefinable (Richards, 2011). Western type menus have become popular in the country, but the traditional Ghanaian type fast food restaurants offer inexpensive authentic foods, which most visitors frequently demand (Ghana Tourist Board, 2005).

Table 1

Percentage of Operations by Regions

\begin{tabular}{lcc}
\hline Region & Restaurant (\%) & Traditional catering (\%) \\
\hline Greater Accra & 42 & 43 \\
Ashanti & 16 & 12 \\
Brong Ahafo & 4 & 6 \\
Central & 7 & 8 \\
Eastern & 8 & 9 \\
Northern & 7 & 4 \\
Upper East & 3 & 3 \\
Upper West & 2 & 3 \\
Volta & 3 & 5 \\
Western & 8 & 7 \\
Total & 100 & 100 \\
\hline
\end{tabular}

Note. Source: Ghana Tourism Federation (GHATOF, 2007). 
Most of these operations are developed in Accra, but there is little effort to adequately address the provision of foodservices at visitor attractions in other locations in Ghana. As a result, they operate at a level well below the expectation of most visitors (GHATOF, 2007).

Table 1 above shows the estimated foodservice operations in Ghana in percentage.

Although available data (see Table 1) indicate the presence of restaurants and traditional operators in Ghana, there is very little discussion or investigation of these types of operations in the literature. In view of the lack of published information, this research undertook primary research in order to identify the different ranges of foodservice activities and operations at visitor attractions. The findings revealed the presence of an estimated number of 2,771 foodservice outlets in the country: 547 restaurants and 2,224 traditional caterers (GHATOF, 2007). Table 2 shows a breakdown of the establishments and personnel.

Table 2

Foodservice and Workforce

\begin{tabular}{lcccc}
\hline Workforce characteristic & Restaurant $(N)$ & \multicolumn{1}{c}{ Traditional $(N)$} \\
\hline Total number of establishments & 547 & & 2,224 & \\
Total number of employees & 8,610 & & 33,000 & \\
Average person per establishment & 16 & & 12 & Male (\%) \\
Access to staff development & 37 & Male (\%) & Female (\%) & 17 \\
\hline Current state of training & Female (\%) & 58 & 83 & 17 \\
\hline Trained staff & 42 & 31 & 35 & 83 \\
Professional staff & 35 & 69 & 65 & \\
Support staff & 35 & & & \\
\hline
\end{tabular}

Notes. Figures are estimates. Source: GHATOF (2007).

\section{Ghanaian Eating Out Habits}

This section draws on the personal experience and observations of the researcher and upon oral narratives, as there is a lack of published data. Until very recently, Ghanaians were not used to eating out of their homes, however, due to education which has enhanced the dual roles of mothers (usually the cooks), it has become common for most families to eat at least one meal purchased from the foodservice outlets, scattered all over the country. Most Ghanaians enjoy heavy meals despite the time of the day. In this regard, as early as 7:00 am, the foodservice outlets provide a varied breakfast menu as shown in Table 3.

Table 3

Type of Breakfast Meals Eaten Outside the Home

\begin{tabular}{|l|l|l|l|}
\hline & Breakfast & Lunch & Supper \\
\hline $\begin{array}{l}\text { Type of } \\
\text { meals }\end{array}$ & $\begin{array}{l}\text { Corn porridge, Kenkey with fish, } \\
\text { rice and sauce, and Wakye (rice } \\
\text { and beans) }\end{array}$ & $\begin{array}{l}\text { Banku with okro stew, Ampesi with stew, Fufu } \\
\text { with soup, Kenkey with fish, fried plantain with } \\
\text { beans stew, and Apapransa }\end{array}$ & $\begin{array}{l}\text { Porridge, rice and stew, Banku, } \\
\text { Kokonte, fried rice, fried yam, } \\
\text { Kenkey, and Wakye }\end{array}$ \\
\hline
\end{tabular}

At lunchtime, the practice of eating out is very high, particularly among workers and schoolchildren. Due to this trend, many schools and institutions now have canteens. However, workers who are mobile tend to move to other foodservice outlets for their lunch. Additionally, those workers without canteens at their workplaces eat from foodservice outlets sited around their workplaces. At the markets, the majority of the traders tend to eat from food vendors who sell their food from the outlets sited in and around the market because of the inability of traders to leave their wares to eat elsewhere. Common foods sold during lunchtime are illustrated in Table 3. 
In the evening, Ghanaians eat from foodservice outlets particularly from those who operate along the roadside with different meals as Table 3 shows.

The above trends suggest a significant demand for the opportunity to eat out in Ghana; this has prompted the setting-up of a range of foodservice outlets of different sizes, which are, in the majority of cases, owner-managed as individuals operate according to their skills acquired in their homes. These outlets are, however, located outside the visitor attractions which equally require such operational diversity.

\section{Benefits of Foodservice Operations at Visitor Attractions}

The primary benefit of foodservice operations particularly at visitor attractions in Ghana is to provide a varied supply of food to visitor attractions to satisfy visitors and sustain their expectations (GHATOF, 2007). Achieving this has the potential to encourage longer stays and repeat visits to the attractions (Long, 2004; Bessiere, 1998). Increase in visitor arrival means increases in foodservice production and, equally, increases in tourism receipts (Morgan, Marsden, \& Murdoch, 2006). These receipts often support the development projects in the country (International Labor Office [ILO], 2010; UNCTAD, 2010). Other benefits are the knowledge acquired by foodservice staff while using modern technology in food preparation (Rogers, 2009). Operating foodservices at the attractions opens job avenues for individuals within the community and in the location (Barke \& Newton, 1995). Food has a particularly important role in the development of tourism services (Hjalager \& Corigliano, 2000), since it contributes 30\% or more of tourist expenditure spent directly with consumption of foodservice products (OECD, 2012).

\section{Providing Foodservice Operations at Visitor Attractions}

In Sheldon and Fox's (1988) investigation on the role of foodservice, they found visitors' habitually patronizing fast foods during lunch and local restaurants at dinnertime. This was influenced by cultural differences among Japanese, United States, and Canadian visitors. The findings of the study suggested that Japanese are likely to sample new products more than their United States and Canadian counterparts are. Conversely, tourists were more concerned about getting value for money at lunch but required quality local cuisine at dinner, at any cost. Due to cultural variances within countries, allowances for socio-cultural changes are invariably, limited among different communities (Mullins, 2005).

The literature suggests foodservice provisions as an important part of visitors' health and well-being, giving an implication for Ghanaian foodservice outlets to adopt initiatives on nutrition and diet (OECD, 2012; Higgings, 2002). It is argued that Ghanaian visitor facilities are currently attracting global attention, as was evident in the celebration of World Tourism Day 2009 in the country (Ghana News Agency, 2009).

Global foodservice operations envisage serving and satisfying customers in any applicable way (Muller \& Dipietro, 2006), to increase production at attractions based on the eating behavior of the visitors (Adjei Frempong, 2010; Sheldon \& Fox, 1988). Visitors demand foods for the attractions to offer a unique and memorable satisfaction that will improve the economic and social well-being of both residents and the travelers (OECD, 2012; UNEP, 2012; Sirakaya, Teye, \& Sönmez, 2002; Hughes, 1995). The need for the foodservice sector supplying adequate food for the experience of both domestic and international visitors to release personal feelings with the products in order to create a good ambience cannot be over-emphasized (Wang, 1999). 
Although researchers and writers have been aware of the potential benefits of offering local/traditional cuisines at visitor attractions, few studies have analyzed the inter-relationship of foodservice and attractions (Sheldon \& Fox, 1988). At the organized workshop at Korea, many authors sought to promote local cuisines as an avenue for tourism growth and for that matter a means of increasing revenues (OECD, 2012) without necessarily applying the concept to the attractions. At the same time, Ghana was not highlighted in the proceedings. Most authors have delved into the issues of tourism and hospitality but focused on other sectors more than the food provisions (Cohen \& Avieli, 2004; Hjalager \& Corigliano, 2000).

Despite the extensive use of food worldwide and benefits such as creating a "comfort zone" for the travelling public (Jacobsen \& Haukeland, 2002), the development of operational techniques is normally geared towards economic gains more than the provision of nutritional and local culinary heritage (Roden, 2000).

This paper, therefore, seeks to contribute to the various assertions made on the importance of developing local/traditional cuisines for the consumption of tourists to tourist attractions, particularly in Ghana.

\section{Methodology}

The study investigated the level of patronage of local cuisines at Ghanaian visitor attractions. A total of 528 (418 international and 110 domestic) respondents to Ghanaian visitor attractions completed a questionnaire which sought information on aspects of food provision at visitor attractions: availability of local foods, texture and taste, preferred foods, and costs. The items included qualitative and quantitative aspects and used the Statistical Product and Service Solutions (SPSS) software to analyze the data collected.

\section{Research Area}

The research was conducted at six attractions in four different regions (see Table 4). Each region highlighted one to two different types of attraction which were located in the country. The sites were selected based on the popularity and the vibrant tourist activities as well as the presence of foodservice outlets. These sites were considered, because they had the available facilities under investigation.

Table 4

Types of Visitor Attractions

\begin{tabular}{|l|l|l|l|}
\hline Region & Cultural attraction & Heritage attraction & Natural attraction \\
\hline Accra & Cultural centre & Museum & \\
\hline Ashanti & Cultural centre & & \\
\hline Eastern & & & Botanical gardens \\
\hline Central & & Castle & Kakum National Park \\
\hline
\end{tabular}

\section{Population and Sample}

Visitors to the six attractions were randomly selected and with their agreement, they were given the questionnaire to respond to the items. Every visitor to the study area was a target for this research. There were no considerations or restrictions regarding age, gender, and/or nationality. In all, 528 visitors to the selected attractions responded to the questionnaire.

\section{Results}

The importance of food as a contributory factor for visitors' length of stay at attractions was rated as being from "of some importance" to almost "very important", as part of the respondents' overall experience at visitor attractions (see Table 5). 
Table 5

Importance of Catering at Attractions

\begin{tabular}{llll}
\hline Nationality & $N$ & Mean & SD \\
\hline Domestic & 108 & $3.43^{\mathrm{a}}$ & 0.73 \\
International & 404 & $2.80^{\mathrm{b}}$ & 0.93 \\
\hline
\end{tabular}

Notes. Importance of food: 1 = No importance; 2 = Some importance; 3 = Quite important; 4 = Very important. Different superscript letters indicate significant differences.

Arguably, value for money is a consideration for any purchase while travelling, and although the research indicated that the price of food provided was generally considered between "good" and "high" at all attractions, the respondents perceived the food as being of "good value for money" (see Tables 6 and 7).

Table 6

Assessment of Current Prices

\begin{tabular}{llll}
\hline Nationality & $N$ & Mean & SD \\
\hline Domestic & 107 & $3.16^{\mathrm{a}}$ & 0.62 \\
International & 327 & $3.02^{\mathrm{a}}$ & 0.65 \\
\hline
\end{tabular}

Notes. 1 = Very low price; 2 = Low price; 3 = Good price; 4 = High price; 5 = Very high price. Similar superscript letters indicate no significant difference.

Table 7

Value for Money

\begin{tabular}{llll}
\hline Nationality & $N$ & Mean & SD \\
\hline Domestic & 104 & $3.02^{\mathrm{a}}$ & 0.57 \\
International & 295 & $3.06^{\mathrm{a}}$ & 0.59
\end{tabular}

Notes. 1 = Very poor value; 2 = Poor value; 3 = Good value; 4 = Very good value. Similar superscript letters indicate no significant difference.

Notwithstanding the "good value" of food served at attractions, texture was appreciated; however, there were no significant differences between the nationalities of the visitors as shown in Table 8 .

Table 8

Characteristics of Food Eaten

\begin{tabular}{lcllcll}
\hline Nationality & Taste $(N)$ & Mean & SD & Texture $(N)$ & Mean & SD \\
\hline Domestic & 93 & 5.37 & 1.39 & 94 & 5.01 & 1.34 \\
International & 266 & 5.41 & 1.11 & 266 & 4.88 & 1.22 \\
\hline
\end{tabular}

Table 9

Type of Food Preferred

\begin{tabular}{llll}
\hline Nationality & Preference for local foods (\%) & No preference (\%) & Total (\%) \\
\hline Domestic & $74^{\mathrm{a}}$ & 26 & 100 \\
International & $59^{\mathrm{b}}$ & 41 & 100 \\
\hline
\end{tabular}

Note. Different superscript letters indicate significant differences.

The interest for local/traditional foods is seen in Table 9 where significant differences exist between domestic and international visitors. Additionally, consuming local dishes is an important part of the visitor experience and it is clear from Table 10 that local food could enhance the visitors' experience at each attraction. There was clear evidence that the availability of local cuisine had an enhancing effect, although there were no significant differences between domestic and international visitors. 
Table 10

Enhancing Effect of Local Cuisine

\begin{tabular}{lccl}
\hline Nationality & $N$ & Mean & SD \\
\hline Domestic & 99 & $5.60^{\mathrm{a}}$ & 1.41 \\
International & 380 & $5.63^{\mathrm{a}}$ & 1.31 \\
\hline Notes. 1 = No enhancing effect; 4 = Neither; and 7 = Significant effect. Similar superscript letters indicate no significant
\end{tabular}
difference.

The idea that offering foodservices at visitor attractions is for the sustenance of visitors and can provide additional revenue in support of the socio-economic sustainability of the location (Hjalager \& Corigliano, 2000) was reflected in the respondents' general propensity to eat at the attractions' outlets, ranking food as part of their overall experience (Sheldon \& Fox, 1988; Jacobsen \& Haukeland, 2002).

\section{Discussions and Conclusions}

As suggested by Morgan et al. (2006), the findings in this study highlighted the provisions of foodservice as an additional income-generating opportunity for the attractions. Confirming other authors, the proposed relationship of foodservices and visitors' attractions in the assessed Ghanaian locations proved potentially valuable in terms of visitors' experience, thus contributing to improving the overall success of visitor attractions (OECD, 2012; Kivela \& Crotts, 2006; Long, 2004; Bessiere, 1998). This suggestion is in agreement with the assertions made by Sheldon and Fox (1988), Hjalager and Corigliano (2000), and Jacobsen and Haukeland (2002).

Visitors' positive opinion on the quality of the food and its value for money could be a motivating factor in opening more outlets at different attractions in order to meet the increasing demands for Ghanaian food and support revenue generation.

Furthermore, it cannot be ignored that individuals' background tends to impact upon their "comfort zones” regarding food habits and choices (Adjei Frempong, 2010; Mullins, 2005), a fact proved at all the attractions, where visitors were generally satisfied with the "taste" of food, but showed concern about the "texture" mainly due to the "difference" from what they would normally consume. Any organized foodservices' operation should take into account the needs of different visitors (i.e., domestic vs. international) as a possible means to encourage repeat buying and increased revenues (OCED, 2012). The results showed that tourists visiting Ghana prefer and desire to experience the culture of the destination through the cultural artefacts such as the customs, flavor, and quality of a variety of local cuisines provided (Wang, 1999).

Similar to other studies, this research concluded that introducing local food is an important part of visitors' overall experience at Ghanaian visitor attractions and that the provision of foodservices' outlets at visitor attractions is still an untapped opportunity for the Ghanaian tourism sector, which has the potential to provide increased revenues and stimulate local economic growth through increased food tourism activities. It is, therefore, necessary for the Ghanaian tourism stakeholders and other interested parties to pay more attention to developing traditional cuisines that will meet the recent trends in food tourism, not only for the various attractions in the country but as organized events within the country. 


\section{References}

Adjei Frempong, A. (2010). The role of culture on food habits and food choices of Ghanaians: The perspective of migrants living in other countries and their impacts on the hospitality industry. Saarbrucken: Lambert Academic Publishing.

Barke, M., \& Newton, M. (1995). Promoting sustainable tourism in an urban context: Recent developments in Malaga city, Andalusia. Journal of Sustainable Tourism, 3(3), 115-134.

Bertella, G. (2011). Knowledge in food tourism: The case of Lofoten and Maremma Toscana. Current Issues in Tourism, 14(4), 355-371.

Bessiere, J. (1998). Local development and heritage: Traditional food and cuisine as tourist attractions in rural areas. In C. M. Hall (Ed.), Wine, food, and tourism marketing. London: Haworth.

Chang, R. C. Y., Kivela, J., \& Mak, A. H. N. (2010). Food preferences of Chinese tourists. Annals of Tourism Research, 37(4), 989-1011.

Cohen, E., \& Avieli, N. (2004). Food in tourism: Attraction and impediment. Annals of Tourism Research, 31(4), 755-778.

Ghana News Agency. (2009, September 30). International writers laud Ghana’s tourism assets. Daily Graphic, p. 1.

Ghana Statistical Service. (2012). Population and housing census 2010. Ghana Statistical Service. Retrieved from http://www.statsghana.gov.gh/docfiles/2010phc/Census2010_Summary_report_of_final_results.pdf

Ghana Tourism Federation [GHATOF]. (2007). National tourism development. Accra: State Publishing Corporation.

Ghana Tourist Board. (2005). Ghana at a glance. Accra: CPC.

Higgings, R. (2002). Response to the joint WHO/FAO expert consultation on diet, nutrition, and prevention of chronic diseases. European Modern restaurants Association.

Hjalager, A. M., \& Corigliano, M. A. (2000). Food for tourists: Determinants of an image. International Journal of Tourism Research, 2(4), 281-293.

Hjalager, A. M., \& Richards, G. (2002). Tourism and gastronomy. London: Routledge.

Hughes, G. (1995). Food, tourism, and Scottish heritage. In D. Leslie (Ed.), Tourism and leisure: Towards the millennium (Vol. 1: Tourism and leisure: Culture, heritage, and participation) (pp. 109-120). Leisure Studies Association.

International Labor Office [ILO]. (2010). Global dialogue forum on new development and challenges in the hospitality and tourism sector and their impact on employment, human resources development, and industrial relations. Sectorial activities department, Geneva. Retrieved from: http://www.ilo.org/sector/activities/sectoral-meetings/WCMS_162201/lang--en/index.htm

Jacobsen, J. K., \& Haukeland, J. V. (2002). A lunch with a view: Motor tourists' choices and assessments of eating-places. Scandinavian Journal of Hospitality and Tourism, 2(1), 4-16.

Kivela, J., \& Crotts, J. C. (2006). Tourism and gastronomy: Gastronomy’s influence on how tourists experience a destination. Journal of Hospitality and Tourism Research, 30(3), 354-377.

Long, L. M. (2004). Culinary tourism. Lexington, United States: University Press of Kentucky.

Ministry of Tourism, UNDP, \& WTO. (1996). National tourism development plan, vision 2010. Accra: GPC.

Molz, J. G. (2007). Eating difference: The cosmopolitan mobilities of culinary tourism. Space and Culture, 10(1), 77-93.

Morgan, K., Marsden, T., \& Murdoch, J. (2006). Worlds of food: Place, power, and provenance in the food chain. Oxford: Oxford University Press.

Muller, C. C., \& Dipietro, R. B. (2006). A theoretical framework for multi-unit management development in the 21st century. Journal of Foodservice Business Research, 9(2/3), 7-25.

Mullins, J. L. (2005). Management and organizational behaviour (7th ed.). Essex: Pearson Education Limited.

Ondimu, K. I. (2002). Cultural tourism in Kenya. Annals of Tourism Research, 29(4), 1036-1047.

OECD. (2012). Food and the tourism experience: The OECD-Korea workshop. OECD Studies on Tourism. OECD Publishing. Retrieved from http://dx.doi.org/10.1787/9789264171923-en

Richards, G. (2011). Creativity and tourism: The state of the art. Annals of Tourism Research, 38(4), 1225-1253.

Roden, C. (2000). Local food and culture, local food, and tourism. International Conference. Madrid: WTO.

Rogers, S. (2009). Functional meals: Technological, practical, and consumer perspectives. Journal of Foodservice, 20(5). 214-223.

Sheldon, P. J., \& Fox, M. (1988). The role of foodservice in vacation choice and experience: A cross-cultural analysis. Journal of Travel Research, 27(2), 9-15.

Sirakaya, E., Teye, V., \& Sönmez, S. (2002). Understanding residents’ support for tourism development in the central region of Ghana. Journal of Travel Research, 41(1), 57-67. 
Torgbuiga, K. (2003). Experience Ghana: Africa’s best kept secret! London: Malinro Ventures.

Torres, R. (2002). Toward a better understanding of tourism and agriculture linkages in the Yucatan: Tourist food consumption and preferences. Tourism Geographies, 4(3), 282-306.

UNCTAD. (2010). The contribution of tourism to trade and development. Trade and Development Board (Second Session), Geneva. Retrieved from http://t20.unwto.org/sites/all/files/docpdf/tourism-note-trade-commission-05-2010.pdf

UNEP. (2012). Economic impacts of tourism. United Nations Environment Programme, Division of Technology, Industry, and Economics. Retrieved from http://www.uneptie.org/scp/tourism/sustain/impacts/economic/negative.htm

Wang, N. (1999). Rethinking authenticity in tourism experience. Annals of Tourism Research, 26(2), 349-370.

Wolf, E. (2006). Culinary tourism: The hidden harvest: A dozen hot and fresh reasons how culinary tourism creates economic and community development. Dubuque, Iowa: Kendall/Hunt Publishing Company. 